\title{
Síntomas limeños: Heterotopías, desfases y riesgos de la capital peruana
}

\author{
Lima symptoms: \\ Heterotopias, gaps and risks in the peruvian capital
}

Rafael Ojeda ${ }^{1}$

\begin{abstract}
RESUMEN
El presente artículo incide en los cambios simbólicos, físicos y demográficos experimentados por la capital peruana durante los últimos cincuenta años. Período en el que Lima terminó de definir su actual imagen de ciudad histórica, híbrida, multicultural y posmoderna, que encierra, dentro de sus límites, todos los matices de una peruanidad determinada aún por aquella tensión permanente entre su faz visible e invisible, de ser una ciudad fragmentadamente legal e ilegal al mismo tiempo. Por lo que, desde un acercamiento histórico, urbanístico y sociocultural a algunos de sus hitos representacionales (Valdelomar, Salazar Bondy, Matos Mar, De Soto), se incide en los actuales riesgos y posibilidades que el proyecto de hipermodernización y consumo, están significando para una ciudad abigarrada e histórica, cuyos flujos heterotópicos son enfrentados a los riesgos unilaterales de una lógica de "urbanomarketización" contemporánea.
\end{abstract}

\section{Palabras clave}

Lima, urbanismo, ciudad, síntomas, crisis urbana, heterotopías.

\section{ABSTRACT}

This article describes the symbolic, physical and demographic changes experienced by the Peruvian capital over the past fifty years. In this period, Lima came to its current image of a historical, hybrid, multicultural and post-modern city. A city that confines, within its boundaries, all the nuances of Peruanity that remain determined by a constant tension between its visible and invisible face, of being a city split between being simultaneously legal and illegal. Invoking a historical, urban and sociocultural approach of some of its representational luminaries (Valdelomar, Salazar Bondy, Matos Mar, De Soto), the article describes the current risks and possibilities that the project of hyper-modernization and consumption has come to mean for a jumbled and historical city, whose heterotypical undulations are faced with unilateral risks of a logic marked by "urban-marketization".

\section{Keywords}

Lima, urbanism, city, symtoms, urban crisis, heterotopias.

La preocupación teórica más importante del urbanismo ha sido siempre los problemas a resolver; ubicando a la ciudad en el horizonte ideal y lineal de un proceso constante de "purificación" o perfeccionamiento progresivo hacia la ciudad-ideal. Lo que nos dice mucho del matiz utópico que ha permitido el surgimiento de la planificación urbana y el urbanismo. Presentándose esto, como el aspecto más importante de su entramado teórico-constructivo, que, en períodos de crisis, ha implicado incluso sustentar la idea de la destrucción de la "ciudad real" para sustituirla por otra "ciudad ideal" que satisfaga las aspiraciones de utopía y bienestar colectivo.

1 Rafael Ojeda es investigador, escritor, ensayista. Ha publicado textos colectivos e individuales. Ha participado en diversos congresos y eventos nacionales e internacionales. Ha sido galardonado por sus investigaciones tanto en el Perú como en el extranjero. 
Es evidente, hasta aquí, que la trampa del urbanismo reside sobre todo en su carácter dependiente y heteronómico. En que este suele beneficiarse del apoyo de los poderes públicos locales y nacionales: la municipalidad y el Estado, organismos que le brindan su legitimidad y prestigio. Por lo que la planificación urbana, que debería dar soluciones a largo plazo para favorecer el desarrollo y la descentralización de la ciudad, se ve arrastrada, por sus empleadores de turno, hacia la resolución de problemas a corto plazo, siendo marcado este por el inmediatismo de los intereses políticos. Sin la posibilidad de conseguir, en este sentido, "convencer a los pobres, que siguen siendo los perdedores del juego urbano" (Dupuy, 1998: 26-27), un juego territorial y político que tiene a la ciudad como su centro de operaciones o campo de batalla.

Y, si dentro de los márgenes nacionales consideramos que este juego compromete a la multiplicidad de la que formamos parte, multiplicidad que podría resumir o definir al Perú como una totalidad integral. Tendremos que existe una palabra que para nosotros podría contenerlas a todas; como síntesis o utopía de lo múltiple, o como "heterotopía" de un país que, en su integralidad, lo resume y condensa todo; como el elemento o segmento fractal de una patria de todas las sangres - como pudo reclamarlo Arguedas-, o desde ese sentido que le diera Valdelomar a la idea de una urbe que sería todo el país. Ciudad cuya escala de síntesis podría catalizar aquella imagen proteica, abigarrada y múltiple característica del Perú contemporáneo, como utopía de la heterogeneidad $e$ imagen gravitacional de lo culturalmente integrador, que atrae para sí todos los significantes y símbolos de lo peruano. En este sentido, la palabra que lo sintetiza todo es Lima.

\section{Lima, la ciudad como concepto e idea}

En la idea de la otrora Ciudad de los Reyes, se sustenta también esa serie de equívocos que fueron desencadenando la originaria "Idea general del Perú". Una idea con efectos residuales en el presente, sobre todo, si consideramos lo complejo y problemático que sigue siendo el abordaje teórico de la capital peruana. Pues antes de la llegada de los españoles a tierras peruanas, ni la idea ni la palabra Perú existían; al igual que, al arribo de estos a la geografía limeña, ni la idea ni el concepto Lima existían. Por lo que, la palabra Lima, pese a algunas posturas o teorías que podrían sostener lo contrario, obedeció también a la misma lógica de deformación y equívocos lingüísticos, desplegados por los "conquistadores" españoles al arribar a tierras peruanas. Quienes a partir de la deformación de una acepción indígena, darán origen nominal a la nueva noción territorial inventada para el Perú, como el centro de lo nacionalsocial, que implicó la edificación de la capital virreinal.

En este sentido, según lo escrito por el Inca Garcilaso de la Vega, la locución 'Lima' se fue derivando de la castellanización de rímac, vocablo que a su vez, era el participio presente activo del verbo "rimay", que significaba "hablar", término que fue imponiéndose a la nominación hispana original de la capital peruana, llamada desde los años de su fundación Ciudad de los reyes. Esto, según el cronista cusqueño, debido a "un ídolo que en él hubo en figura de hombre, que hablaba y respondía a lo que le preguntaban, como el oráculo" (Garcilaso 1959: 352-353). No obstante ello, algunos historiadores y lingüistas han afirmado que el proceso de evolución o transformación de la palabra Lima habría sido inverso. Aurelio Miro Quesada, por ejemplo, ha escrito que "La pronunciación del quechua de la costa era la "l" y no la "r", como lo afirma claramente el padre Cobo" (Miro Quesada, 1994: 17). Por lo que, según acotación que hiciera el mismo padre, deberíamos traducir Lima como la "ciudad que habla" (Ibíd.).

En este sentido, la historia de Lima nos dice que cuando Pizarro arribó a estas tierras, el curaca o señor principal del señorío era TauriChusco; y que la otrora Ciudad de los Reyes fue fundada un 18 de enero de 1535, día en el que Francisco Pizarro, acompañado de Nicolás de Rivera el Viejo, la fundara sobre los dominios del mencionado curaca, instaurándose, desde entonces, la idea de la ciudad colonial que determinó la ruptura geopolítica definitiva de la antigua configuración andina del Perú. Pues 
la fundación de Lima implicó el abandono del Cusco - antiguo centro de poder inca-, para instaurar como centro de poder político, militar y religioso del virreinato peruano, a una de las relegadas periferias del Tahuantinsuyo. Evento que, además de edificar un nuevo centro geopolítico, determinó que el diseño urbano, vigente durante la Colonia, pasara a ajustarse a ideas propias del Renacimiento, que a su vez eran la reelaboración mejorada de ideales griegos y romanos.

Así, desde su configuración inicial, Lima, como las ciudades criollas más importantes del resto del país, se fue caracterizando por su trazado racionalizado y regular en forma de cuadrícula o damero, con calles geométricamente regulares, cortadas en línea recta, que delimitaban manzanas rectangulares y uniformes. Pero pensada, desde el principio, como centro político, social y militar. Convirtiendo, a la ciudad nueva, en el foco magnético que lo fue atrayendo todo, en el lugar en el que fueron convergiendo las concentraciones políticas, las diversiones, la economía, la población y las diversas manifestaciones culturales del país. Por lo que, desde ahí, debido al añejo centralismo existente, Lima se fue erigiendo también como el eje geopolítico y urbanístico del Perú, irradiando su fascinación y apuesta por la modernidad sobre las aspiraciones urbanas del resto de ciudades peruanas, que fueron siguiéndole en orden e importancia. Sobre todo porque la mayoría de capitales y ciudades del interior del país, en sus aspiraciones de modernidad, han tendido o deseado ser como Lima o, en su defecto, parecérsele.

De ahí que urbanística y arquitectónicamente, las representaciones de la capital peruana deambulen entre la noción de ciudad tradicional, sustentada en los rezagos coloniales, neoclásicos y republicanos de su centro histórico, político y administrativo (Lima Cercado); la concepción de metrópoli global, homogeneizada en torno a una estética moderna, cosmopolita y reticular, que define a sus centros económicos y financieros (Miraflores y San Isidro); y una idea de heterogeneidad, derivada de la multiplicidad de estéticas o tendencias históricas y urbanísticas, que fracturan la geografía de Lima, entre la representación de una ciudad legal y otra ilegal, como un complejo urbano funcional, abigarrado y posmoderno; en el que coexisten, producto de las migraciones y el crecimiento caótico de sus márgenes, una estética urbana de centro y otra de sus múltiples periferias; a partir de formas arquitectónicas enfrentadas en sus diferentes polos de desarrollo, y una imagen abigarrada, caracterizada por la precariedad y ausencia de diseño, propias de la informalidad que se ha ido asentando, sobre todo en los distritos más populosos de Lima.

\section{Ciudad legendaria vs. ciudad real}

Quizá ha sido el eufónico nombre Ciudad de los Reyes ${ }^{2}$, el que ha ayudado a reforzar aquella deslumbrante imagen de "arcadia colonial" que desde sus orígenes ha ido proyectando Lima, ciudad que suele sustentar todo su prestigio en un pasado glorioso y colonial, definido ya hacia 1708 , por Pedro Peralta y Barnuevo, en su Lima Triunfante, imagen de una ciudad devastada por el terremoto de 1746, que dejó la colonia en ruinas (Walker, 2012); pero presentada luego, como una ciudad heroica, cuya historia se difumina en la nostálgica creencia criolla de ver al pasado colonial como una suerte de paraíso perdido, o "Arcadia colonial", según dijera hacia 1964, Sebastián Salazar Bondy. Urbe caracterizada, en la actualidad, por su imagen de ciudad poliédrica, que enfrenta espacios de renovados aires de modernidad a lugares históricos pauperizados, colapsados $e$ informales, que la han elevado a la condición de urbe cosmopolita y multicultural, que condensa una estética internacional, que la asemejaría a otras ciudades modernas del mundo $-y$ por extensión, sobre todo en sectores hegemónicos, hipermodernos

2 Desde su fundación en 1535, Lima fue llamada la Ciudad de los Reyes, dícese que en homenaje a Carlos V y doña Juana, o, como dijeran otros, en conmemoración de los Reyes Magos. Creencia asentada debido a que durante mucho tiempo se creyó que la fundación de Lima había sido un 06 de enero de 1535, y no un 18 de enero, como sabemos actualmente. Véase Leguía, Jorge Guillermo (1989: 43-44). 
y reticulares, a lo que Saskia Sassen ha llamado "ciudad global" (Sassen, 1999)_; con otra ciudad historicista, de características coloniales y republicanas - también asonantes a un orden internacional clasicista-, además de aquella estética informal y aleatoria, característica de los márgenes y periferias suburbanas, espacios urbanísticamente sustentados en la improvisación, en la solución de urgencias pragmáticas esenciales, sobre la vía constructiva del aglomeramiento y la aleatoriedad pura.

Tal vez por ello, podemos decir que Lima, desde su configuración inicial, que obedecía a un ordenamiento en forma de damero, se ha transformado estructural y simbólicamente. Pasando de ser una "ciudad amurallada" en contra de los ataques de filibusteros, en 1685, de ser llamada "ciudad legendaria" por Jorge Guillermo Leguía (1989), conocida también como "Ciudad jardín", debido a un tópico de referencias urbanísticas, anglosajonas tomadas de Ebenezer Howard -idea con la que la ciudad-capital sería representada por incontables viajeros europeos que pasaron por el Perú-, a su imagen actual de ciudad caótica, múltiple y policéntrica. Esto debido a que aquella imagen áurea que la caracterizara, la acompañará solo hasta la primera mitad del siglo XX. Período que ha significado el tránsito y clausura definitiva de la noción de ciudad tradicional —celebrada aún por los aristocráticos gustos coloniales que siguieron a la República-; hasta la "despedida nostálgica" prevista ya hacia 1921, en Una Lima que se va, de José Gálvez, quien denunciaba el inicio de las demoliciones de los clásicos lugares de la vida antigua y el comienzo de un avasallante proceso de urbanización (1965: 261).

En este tránsito, la capital peruana dejó de ser la simbólica "dorada Lima" de Bertolt Brecht (1980: 88), para convertirse en la ciudad real y expansiva; convulsionada por algo que solo algunas décadas después, hacia 1984, dará origen a lo que José Matos Mar rotuló como Desborde popular y crisis del Estado, ante el rebase político que implicaba la crisis institucional, los vacíos de gobernabilidad, la ineficacia estatal, la informalidad y la incursión de nuevos sujetos políticos y sociales -producto de las migraciones campociudad- deambulando en una cartografía urbano-capitalina que tendía a extenderse y transformarse.

Así, la ciudad continuó creciendo desordenadamente. Aumentando la tugurización y el hacinamiento de sus barrios antiguos, y la precariedad e inseguridad de sus barrios nuevos, o "pueblos jóvenes", que fueron extendiéndose masivamente. Resultando de ello, la configuración crítica de un urbanismo colapsado, en una ciudad en la que el transporte urbano, que debería interconectar fluidamente todos los espacios metropolitanos, automatizando la vida urbana $e$ integrando operativamente a la ciudad, fue provocando congestión y caos, además de grandes pérdidas económicas en términos de horas laborales.

No obstante ello, con el paso de los años, debido sobre todo a los procesos de hibridación costumbres y sincretismo cultural característico a lo popular, desde un punto de vista menos urbanístico y más antropológico y demográfico, se fue edificando la historia alternativa de una ciudad marginal y marginada; historia en la que, a la "ciudad visible", oficial y tradicional, se le fue contraponiendo una "ciudad invisible" - como realidad negada por el discurso hegemónico de la hermenéutica añeja de la Lima histórica-, que, a partir de la diseminación de los productos más representativos de la cultura popular, fue asentando su protagonismo, hasta imponer, desde los intersticios, márgenes y periferias suburbanas -espacios antes reservado solo a los marginales y desadaptados de la metrópoli-, en lo informal, lo mestizo, lo fusionado, lo cholo o lo chicha, su rostro más desesperado, pero también el más colorido, bullente y dinámico.

En este sentido, incidiendo en esta suerte de confrontación urbana, dos décadas antes que Matos Mar, Sebastián Salazar Bondy, en su ya célebre libro Lima la horrible, de 1964, había esbozado ya las sintomatologías emocionalmente críticas de la nueva ciudad. Irrumpiendo críticamente en los síntomas de una sociedad metropolitana que, hacía 
solo cincuenta años atrás, adolecía aún de abundantes resabios señoriales, coloniales y aristocratizantes, residuos que sostenían esa ideología criolla, hispanizante y excluyente de dominación, que en la idea de "Arcadia colonial", solía caracterizar aún, a la tradicional mentalidad criolla de la población "originaria" de la capital. Al escribir que los limeños vivimos "Como si el porvenir y aún el presente carecieran de entidad" (Salazar 1974: 13), pues existimos saturados de un pasado que ha sido impuesto por quienes, desde su lugar de enunciación y estatus antropológico y social, "creyeron desentrañar el enigma de nuestro ser" (Loc. cit.); sobre todo porque el pasado nos atrae, en la medida en que vivimos supeditados o alienados por este, y por el que desdeñaríamos el presente.

En Lima la horrible, partiendo de la idea de Raúl Porras Barrenechea, que dijera que Lima es una ciudad impregnada de una "extraviada nostalgia"3, Salazar Bondy propone como uno de los mayores responsables de estas "dosis alucinógenas" a Ricardo Palma y sus tradiciones: "el más afortunado fabricante de aquel estupefaciente literario" (Ibíd. 14). Macando también una tradición de apostasía al mito colonial, que parte desde Manuel González Prada, que será continuado por José Carlos Mariátegui y será seguido por algunos críticos de la ciudad de nuestros días. Enfrentando así, a un discurso todavía hegemónico durante aquellos años, discurso que invocaba a una Lima señorial, añorada por muchos como "Arcadia colonial", como idea presentada como narrativa y discurso ideológico útil para legitimar un sistema criollo de segregación y dominación. Sistema en muchos aspectos "antinacional", que fue confrontado con un discurso alternativo que extendía la historia de Lima más allá del día de su "creación", es decir en su período prehispánico, en los que se ubican albores de una ciudad emergente, inclusiva y diferente.

Esto, debido a que el recurso al período colonial, idealizado en la idea de "arcadia", servía para ocultar y legitimar aquella violencia real, supérstite a la emancipación. Un discurso propugnado aún, desde aquellas pulsiones criollas nostálgicas, por los que han anhelado reconstruir la idea histórica de un Perú señorial, no obstante que experimentan un espacio metropolitano, en el que las tensiones urbanas, las fisuras sociales y los conflictos de clase entre amos y siervos, extranjeros y aborígenes, potentados y miserables, eran ocultados tras su devoción al espejismo áureo de la "ciudad legendaria" y colonial, la que se ha pretendido imponer sobre la ciudad real. Tema que podría suscitar debates en torno a argumentos análogos, entre tradicionalistas y modernistas, a los surgidos en aquella proverbial querella entre antiguos y modernos, inscritos en la larga historia del pensamiento occidental; desde disputas que podrían remontarse hacia una prolija tradición representacional de Lima. Representada como una ciudad fracturada, confrontada entre sus márgenes cardinales y metropolitanos, desde aquella noción de "Arcadia colonial", con sus diversos apólogos, como Ricardo Palma y José Gálvez, hasta la idea de Lima como una ciudad horrible, ideologizada, colapsada y antidemocrática, de nuestros días.

\section{Tensiones ciudadanas y abigarramiento metropolitano}

Conlacaídadelmitodeldesarrolloylaconciencia de la crisis propagada en todos los niveles de vida en sociedad, crisis diseminada hasta en la vida privada, mucho de las evaluaciones urbanísticas tradicionales ha ido perdiendo sentido. Pero en la dicotomía campo-ciudad, si analizamos esto en términos funcionales, hay un factor que le da al espacio urbano un atractivo especial. Atractivo cimentado en las tesis tecnocráticas que han ubicado a la ciudad como eje de industrialización, modernidad y progreso, quedando lo rural como espacio de premodernidad y producción artesanal, en el que el tiempo parece haberse detenido por su primitivismo. Infiriéndose de esto una lógica interna que regiría de los desplazamientos. Una historia que haría de los problemas personales también problemas sociales.

Gilles Deleuze en su libro Crítica y clínica $(1996)^{4}$, deslizaba la idea de que los escritores $y$ artistas pueden ser vistos como grandes

\footnotetext{
Citado en Lima la horrible (Salazar, 1974: 11)

4 Esto se hace más evidente si consideramos su estudio Presentación Sacher-Masoch, (Deleuze, 1973).
} 
sintomatólogos de los males sociales, incluso de los trastornos civilizacionales. Por lo que sus obras o escritos albergarían o describirían síntomas de malestares que suelen trascender lo personal-individual, o partir desde ellos, para alcanzar dimensiones sociales o societales. De esta manera, podríamos ver en sus diversas representaciones de la sociedad o de las ciudades contemporáneas, los síntomas de un síndrome o malestares sociales que, en el caso de Lima, estarían tendiendo a prolongarse por demasiado tiempo.

De ahí que, tal vez han sido los últimos cincuenta años, los que han albergado el contexto trascendental de autoconciencia $y$ de cambios urbanos y poblacionales, que se han manifestado como los residuos de conflictos políticos y sociales que, durante todo este tiempo, han aquejado a la capital peruana. Cambios que determinaron el tránsito y clausura definitiva de la noción de ciudad tradicional, para dar paso a la actual configuración de Lima: una ciudad convulsionada por el desborde popular, ante la inmersión de nuevos sujetos o actores sociales. Lo que ha hecho que la ciudad capital haya dejado de ser ya la aclamada "Ciudad jardín", para convertirse en Lima la horrible, si tomamos como rótulo descriptivo el efectivo título que Sebastián Salazar Bondy, tomara de la referencia de fechas de algunos de los versos de César Moro. Rótulo que, como fraseología clínica, pasará a canalizar el sentir de toda una tradición de discursos articulados en contra de Lima -o al menos en contra del discurso oficial con el que se ha construido la idea de Lima y lo limeño-, planteando a la vez una forma nueva de relacionarse con la ciudad. Una ciudad conflictivamente amada, pero también debido a ello, objeto de continuos desprecios y resentimientos.

No obstante, o específicamente por ello, el espectro de acción de los sectores sociales que han venido caracterizando a Lima, han evolucionado o mutado ante la agudización de los conflictos sociales; donde las crisis medioambientales, la situación de insalubridad y la degradación moral que se fue ampliando rápidamente durante las últimas décadas, produjo que los sectores, otrora ubicados en los márgenes o cinturones de miseria de la capital, como mecanismo de inserción y supervivencia que les permitió salir adelante en una sociedad que los excluía, irrumpieran paulatinamente en el centro y en los alrededores de algunos distritos criollos de la gran Lima. Hasta edificar ese mercado paralelo y al margen de las instituciones legales, que dio origen al ya lejano boom comercial de Gamarra, como empuje o pulsión de lo informal, que alcanzará su apoteosis durante las difíciles décadas del ochenta y noventa, del siglo pasado, período marcado por la violencia política determinada por el conflicto armado iniciados por los grupos subversivos PCP-SL y el MRTA, contra el Estado peruano.

Tal vez debido a esa eclosión de lo multitudinariamente migrante, $y$ sus pugnas en pos de su inserción económica y social, se construyó así, en la informalidad, un espacio económico y vivencial alternativo, que les fue permitiendo morar, producir, comerciar y desplazarse, en un escenario en el que el Estado en crisis, con un serio vacío de poder y una débil legitimidad, no podía responder ante las remozadas presiones de las masas. Población que, ante la ineficacia del orden político y la legalidad jurídica, solo le quedaba la posibilidad de satisfacer sus necesidades vitales o vivenciales, rebasando el orden establecido, la norma, lo legal, lo oficial y lo formal, en búsqueda de asentarse y subsistir en los alrededores de ese soñado centro, presentado como el espejismo o la utopía de la buena vida. Centro aspiracional que organizara y solucionara todos los problemas y carencias de sus míseras vidas.

Resulta claro, por ello, que Hernando de Soto, en su libro El otro sendero (1987), esquematizara ese proceso de informalización en cuatro niveles: el de la industria informal, el del comercio informal, el del transporte informal y el de la vivienda informal, pero cabría agregar aquí que la existencia de la ciudad informal, edificada producto de las invasiones y ocupaciones ilegales de tierras, se fue desarrollando sin idealizaciones $\mathrm{ni}$ racionalizaciones, ni un trazado urbano ni planificación que las guíe. Sobre todo, porque sus habitantes se han sentido siempre 
extraños en el campo del urbanismo. Un urbanismo que, en este contexto, se presenta como culpable, pues cuando ya no puede basarse en la comprensión real y actual de la vida ciudadana, una vida urbana que se ha desarrollado al margen de este urbanismo, se ve confrontado con su incapacidad para organizar la ahora "gran ciudad"; en terrenos en los que incluso la intervención política del Estado, ha resultado ineficaz. Pues la ciudad así constituida, como urbe ilegal o informal, para poder terminar de concretarse, al albergar los múltiples sueños de prosperidad y de progreso o tal vez simplemente los afanes de supervivencia de sus nuevos aspirantes a ciudadanos, ha tenido que desarrollarse en contra de la ciudad y del urbanismo mismo.

De ahí que si nos detenemos en conceptos como nación, que tienden a definir los ideales de una comunidad política homogénea, como comunidad imaginada, para decirlo en términos de Benedict Anderson (1993), o como "ciudad imaginada" para nuestro caso; veremos que Lima viene a plasmar esa ficcional idea de integración nacional, impuesta un como relato de dominio colectivo compuesto por significados, símbolos $e$ imaginarios urbanos, antiguos y nuevos, que han cimentado la creencia de que habitamos un espacio teórico-normativo homogéneo, puntal de la modernización del país; cuando, en lo social y cultural, la capital se presenta como una entidad heterogénea y conflictiva, agobiada por el desborde urbano $e$ institucional, con una población abigarrada entre lo funcional de la planificación política, y una informalidad definida en su precariedad, anomia social y ausencia de un control estatal; además de sus múltiples formas enfrentadas de ciudadanía y de aspiraciones a ciudadanía, formas que pasaron a encarnar turbulencias urbanas, económicas y sociales, que han pretendido ser resueltas al margen del control del Estado.

\section{Mapeo urbanístico y fracturas sociales}

Tradicionalmente, la ciudad ha sido concebida como centro de producción cultural, foco de conformación democrática y eje de constitución social; por lo que, al no poder responder a los desafíos planteados por el crecimiento caótico de sus periferias y a los síntomas caóticos de su desborde -desborde producido por las múltiples olas migratorias campo-ciudad-, en márgenes que dieron origen a amplios sectores de desgobierno y vacíos legales, pasó a ubicarse en las fronteras mismas de un colapso anunciado por las tendencias e índices demográficos y poblacionales. Por lo que, resulta evidente que el fracaso sociopolítico del Estado, y el de las instituciones municipales, ha implicado también el fracaso de la ciudad $y$, con ello, el de un urbanismo distante de la realidad social.

En este contexto, si buscamos una solución efectiva al presumible colapso metropolitano, debemos plantear una transformación profunda en la manera de concebir y, por lo tanto, de traducir territorialmente los nuevos sistemas de referencia espacio-temporales. Sistemas creados por ese nuevo status quo, originado en las zonas marginales, por aquella población otrora marginal, que luego se hizo informal, y que, a estas alturas, ha logrado convertir a sus ciudades - Lima norte, Lima sur y Lima este- en focos autónomos de producción y desarrollo. Sobre todo porque, durante todo este tiempo, Lima había sido, no solo el centro de tensiones políticas, estéticas y sociales, polarizadas entre distintas formas urbanas de ver y asumir la ciudad, sino también el eje de conjunción de distintas emociones confrontadas; visiones que gravitan entre lo tradicional, lo modernizado y lo moderno, además de aquella aura de ciudad multicultural, prevista o pensada aún como caótica, pero desde una configuración que ha tendido, si seguimos algunas definiciones caras al urbanismo y sociología histórica, entre aquella imagen de ciudad colonial, idílica pero excluyente, y la de una ciudad colapsada, pero en apariencia democrática e integradora de las diferencias.

Por lo que, es debido a esa suerte de determinismo económico, al momento de intentar construir una imagen profana de la capital, una imagen marcada por las tensiones existentes entre precariedad y riqueza, entre pobreza y prosperidad, con sus equivalentes territoriales, que podemos asumir que el 
crecimiento de Lima, durante todos estos años, ha sido básicamente horizontal, y no vertical, como ha sido el caso de otras ciudades importantes de América Latina. Es decir, no ha densificado sus centros sino extendido sus extremos hasta encontrarse con otras ciudades no metropolitanas. En este sentido, solo un pequeño sector de la clase media nativa limeña, ha preferido vivir en grandes edificios ubicados en Miraflores y San Isidro; mientras el resto optó por viviendas unifamiliares ubicadas en lugares distantes y distintos de la ciudad.

De ahí que el centro histórico, otrora sede de la elite criolla, fue paulatinamente tomado por sus nuevos ciudadanos que empezaron a hacinarlo. Por lo que, ante la irrupción de nuevas oleadas de migrantes, sus no tan antiguos habitantes fueron proliferando hacia los viejos barrios mesocráticos. En un acomodamiento y reacomodamiento urbano, que hizo que los distritos que fueron concentrando el mayor índice de riqueza sean Surco, La Molina, San Isidro, San Borja y Miraflores, con un 98\% de habitantes del sector "A". En tanto, un aproximadamente $20 \%$ de la población de Lima Metropolitana se concentraba en barrios residenciales de los sectores medios y altos; mientras el $80 \%$ restante vive en asentamientos urbanos populares. De los cuales, del $80 \%$ de la población considerada como habitante de estos sectores populares, casi el $37 \%$ radica en barriadas, el $23 \%$ en urbanizaciones populares y el $20 \%$ en tugurios, callejones, corralones y asentamientos humanos diverso tipo (Matos Mar, 2005: 69).

Así, la imagen actual de Lima metropolitana, continúa marcada por ese matiz andino $e$ informal que fue emergiendo desde las primeras generaciones de migrantes. Pues los edificios coloniales, el Palacio de gobierno, la Catedral de Lima, además de otros lugares específicos de Lima cuadrada, que aún podrían ser representativos de lo que José Gálvez llamara "la vida antigua", se han ido contrastando con una estética de feria, nueva e híbrida, impuesta por la necesidad de reafirmación identitaria, reforzada desde lo oficial, como recurso turístico, que ha ido integrándose a aquello que en los últimos años, desde el Estado, se ha venido a llamar Marca Perú. Sobre todo porque, como sostenía Matos Mar hacia 1984: "Lima cuadrada virreinal, ha venido cristalizando ese nuevo rostro desde la década de 1960. Se ha hecho ajena, por vez primera en nuestro proceso histórico, a los sectores opulentos y medios. Sus calles adquieren el aspecto de ferias provincianas" (2005: 79).

De esta manera, se fue dando en Lima un proceso de miscegenación antropológica, que con el paso de los años fue generando un tipo cultural urbano diferente. Cuya subjetividad, sustentada en el paradigma de lo cholo y lo chicha, se fue transformando cultural y socialmente, en el discurso ideológico y limeñocéntrico hegemónico. Un discurso enarbolado oficialmente, hasta los días previos a los trágicos acontecimientos de Bagua, ocurrido entre mayo y junio del 2009, recordado como el Baguazo, que hizo que todos los sociólogos criollos, repetidores del discurso de la cholificación nacional (Quijano, 1980) y el de la choledad (Nugent, 1992), planteada como la esencia monolítica de una noción de peruanidad oficial y excluyente, se enteraran por fin de que en el Perú la alteridad todavía no se había disuelto, y de que no habitamos en ese publicitado país homogéneo en el que "todos somos cholos"; sino en un país en el que, en grandes sectores del Perú profundo, aún existen grandes cantidades poblacionales de peruanos indígenas, inmersos aún en una problemática que, desde los inicios del período republicano ${ }^{5}$, aún esperan ser resueltas.

En ese contexto, lo cholo, culturalmente presentado como un arquetipo derivado del encuentro entre el patrimonio traído por el migrante, que se ha ido arraigando en el antiguo residente limeño de las periferias, además en las segundas y terceras generaciones urbanas, se fue, con el paso del tiempo, homogenizando hasta convertirse en un distintivo cultural nuevo, que, a partir del soporte teórico de lo mestizo y lo híbrido,

5 Uno de los escritos incluidos en los 7 ensayos de interpretación de la realidad peruana, de Mariátegui, lleva por título, precisamente, "El problema del indio" (Mariátegui, 1991: 45-57). 
pasó a caracterizar a la nueva cultura popular limeña. Una tendencia hacia la reafirmación simbólico-identitaria de la población peruana, que ha dado origen a un enfoque más integral, al menos simbólicamente, de lo nacional. Un proceso que en su fase económico-oficial, tiene su correlato en la política turístico-comercial promovida por el Estado, denominada Marca Perú. Una campaña que busca empoderar internacionalmente al país, como un mercado en el que se expenden productos característicos a la "peruanidad", a partir del uso o articulación comercial de sus complejas expresiones etnográficas, iconografías, culturales, artísticas; de sus productos tradicionales, agrícolas y gastronómicos; además de la venta de productos y estilos de vida que, hasta solo hace algunos pocos años atrás, eran considerados exóticos, folklóricos o no "nacionales", debido al reducido espectro de su ubicación o localización geográficosocial.

\section{La ciudad zombi ya no habla solo vende}

Transcurrido cincuenta años tras la publicación de Lima la horrible, aquella tendencia reduccionista y limeñocéntrica, identificada territorialmente con la capital peruana, como un discurso ideológico que ha pretendido ser impuesto como verdadero nacionalismo para todo el país, y "que por medio de sus valores negativos excita el sueño vano de la edad dorada reyes, santos, tapadas, fantasmas, donjuanes y pícaros" (Salazar Bondy, 1974: $35)$, parece haber cedido ante la emergencia de un discurso cultural $e$ identitaria de síntesis, que tendría como referentes una aún pretendida cultura peruana. Una noción actualmente reforzada por una campaña que - si es evaluada desde su versión positiva y no "mercantil" - está produciendo también el recuperamiento o la toma de conciencia ante expresiones artísticas y formas culturales pertenecientes a grupos étnicos antes invisibles o ausentes en el mapeo poblacional, político y económico de la cultura e industria cultural popular peruana. Lo que podría suscitar aún, la ilusión de que, al asumir un discurso integrador de este tipo, se estaría tomando partido también por un tipo de "nacionalismo" añejo, que transformado en "limeñismo", no ha dejado de identificar al Perú con Lima.

Por lo que, en este sentido, la ciudad actual ha pasado a albergar contradicciones centenarias. Como problemas previstos desde el conflicto fáctico entre tradicionalistas y modernistas, manifiestos en un espacio metropolitano de tensiones y vías múltiples, entre utopistas arcaicos y gerentes modernos y proactivos, enfrentados sobre la base de un antagonismo permanente, que enfrenta un celebrado $y$ añorado pasado de armonía y fastuosidad, frente a un presente desbocado, heterogéneo, vertiginoso y caótico. Contradicciones en las que lo legendario y lo hiperreal, debido a lo angustiante de su evidencia, se ven agobiados por un proceso soporífero de "urbanomarketización" generalizada, en un mercado de beneficios, regido por una lógica neoliberal, que viene imponiendo su nueva "estética" en Lima. Un modelo que tendrá siempre como víctimas desprotegidas a los sectores más desfavorecidos y excluidos de la población.

No obstante ello, a estas alturas, sobre todo, debido al estado crítico de la capital, deberíamos ponernos a salvo del riesgo de tener que aceptar visiones urbanas distorsionadas como alternativas de solución. Esto, debido a la crisis no solo material, sino espiritual que experimenta la población limeña, una crisis motivada por la urgencia que tenemos de un nuevo mito modernizador que cambie la actual configuración urbana, a todas luces desbordada y colapsada. En la que la capital peruana se presenta como un espacio que no deja de derruirse y reconstruirse simultáneamente. Sobre todo porque las actuales ilusiones y deseos de modernización, están erigiendo, sobre la base de un centralismo remozado -en el que la capital del Perú es el Perú-, un nuevo espejismo de prosperidad ligado al crecimiento económico del país, que está haciendo que el ideal de desarrollo, asociado aspiracionalmente a la bonanza y al beneficio económico que esto conlleva, devenga, entre otras cosas, en el ideal "nacionalista" de la campaña llamada Marca Perú —estrategia de marketing que en resumen encarna la idea de un país en el que todo debe comercializarse 
o venderse-, que está deviniendo en aquella peligrosa analogía modernidad-mercado, asociación que en el espectro urbano está produciendo una mayor "contaminación visual" o desagregación estética para la ciudad. Ciudad que, debido a la construcción indiscriminada y sin criterios de "impacto urbano"6, de modernos centros comerciales, de malls fosforescentes y la proliferación creciente de edificios residenciales dinamizados por un boom constructor e inmobiliario, ve reducir cada vez más sus posibilidades museables $e$ históricas. Por lo que ha tenido mucha razón Robert Venturi al afirmar que "La arquitectura moderna lo ha sido todo menos tolerante: sus arquitectos prefirieron cambiar el entorno existente a mejorar lo que estaba alli" (2000: 22), refiriéndonos en este caso a la arquitectura hipermoderna.

En este punto, a este tipo de "contaminación" urbanística y arquitectónica, se suma la profanación sonora y ambiental del espacio monumental e histórico limeños; sumados también los espacios caóticos de la Lima no histórica y hasta los de la Lima antihistórica, además de sus intersticios y fisuras resimbolizadas, depredadas o pauperizadas, que han dado lugar a una serie de nuevas tensiones, que, para ser enfrentadas, deberán pasar primero por la posibilidad de recuperar a la ciudad histórica, pero no como el remedo excluyente, antidemocrático y aristocratizante del espejismo arcádico de la colonia, que albergaría a esa suerte de ciudad muerta y hasta cierto punto museística; sino bajo la idea de una ciudad múltiple, integral y vital, de posibilidades históricas-museables, vivenciales y futuras para todos, pero desligada de esa idea de urbanismo cuasi escenográfico, que empieza a imponer su "estética" auspiciada por los al mismo tiempo nuevos y tradicionales ideales inspirados por la sociedad de consumo.

Así, Lima se presenta como una aspiración revalidada desde aquella incumplida promesa de la vida peruana, que produjo el fallido discurso criollo de la emancipación y el de la promesa de igualdad y justicia republicana.
Una República pensada como experiencia de la libertad, pero como una experiencia materializada en una libertad defectuosa y plagada de muchas fisuras opresoras, discriminadoras y coloniales. Por lo que, ante esta evidencia de antagonismos eviternos, en oposiciones que comprometen dicotomías como la de una ciudad museable y la de una urbe shopping-city-mall, parece ser que es la segunda la que terminará prevaleciendo, hasta hacer tabula rasa de la primera. Acabando así con la posibilidad de rescatar a la ciudad histórica y mantenerla en pie para las futuras generaciones. Sobre todo porque es esta tendencia constructiva, asociada a la estética del mercado neoliberal, la que termina por adaptarse mejor al diálogo crítico, conflictivo y hostil de la condición estructural de la sociedad limeña, seduciendo también a la imagen de su ciudad, reprensada como espacio de la vida colectiva. En la que, la debilidad por el consumo, apunta también a sus propios paraísos arquitectónicosurbanísticos-comerciales, cuando no lo hacen hacia aquella noción constructiva, marcada por el eclecticismo radical del posmodernismo arquitectónico e historicista de ciudades de casinos y juegos, como Las Vegas (Venturi; Scott Brown, 1971).

En este sentido, de cara a los cambios de configuración que experimentará la ciudad en los años sucesivos, años que la llevarán hacia los fastos del bicentenario de la Independencia y hacia la celebración del quinto centenario de su fundación como capital peruana -lo que lo hace más grave aún esta tendencia-, es que en Lima cuadrada, como en casi todas las provincias y distritos históricos del Perú, el hechizo de la modernización está generando atrocidades arquitectónicas y urbanísticas, ante la inacción y el mal gusto de las autoridades culturales, municipales y estatales que deberían velar por el ornato, belleza y eficiencia de la ciudad, pero que, en líneas generales, promovidos por sus intereses políticos y personales perentorios, no lo hacen o lo hacen mal. Legitimándose en discursos que presentan la experiencia de la modernización

\footnotetext{
6 Léase esto como un estudio de "impacto ambiental", pero como recurso constructivo aplicado a la ciudad.
} 
y la del libre mercado, como la panacea que redimirá todos los males sociales, además de todos los síndromes de la condición urbana de la ciudad-capital. Encubriendo así al otrora célebre discurso de la ciudad republicana, histórica $y$ de dimensiones estéticas invaluables. Un discurso de corte historicista que a estas alturas, para algunos, ya podría sonar un tanto descabellado y pasatista, pero que podría ser asociado a la ratio de ciudadesmuseo eficientes y dinámicas como Roma, Londres o Paris.

Todo esto podría hablarnos del extraordinario valor simbólico-discursivo de una ciudad como Lima. Urbe que, cercana ya al quinto centenario de su fundación, se presenta como una ciudad histórica y tradicional, pero a la vez como una ciudad múltiple, híbrida $y$ abierta hacia un futuro incierto, como el de sus habitantes. Tal vez por ello, hace algún tiempo y en algún lugar Vargas Llosa decía que Lima, cuyo centro está ocupado por edificios abandonados e inconclusos, encarnaría el temperamento terminal de los limeños, que suelen empezarlo todo y casi no terminar nada. Y esto, que podría definir la labor de los continuos alcaldes que ha tenido que experimentar o sufrir la ciudad durante los últimos cincuenta años, es decir desde la época en la que circuló por primera vez Lima la horrible, de Sebastián Salazar Bondy hasta nuestros días, nos dice que tal vez en el retorno al pasado, es decir en el análisis y la correlación de la ciudad histórica con la ciudad real y concreta del presente, se pueda hallar los nexos y parámetros olvidados al momento de querer entender o asir la complejidad de la capital peruana.

\section{Lima y el peligroso silogismo de la peruanidad}

Es un hecho innegable el efecto afirmativo y nacionalista que puede haber tenido la exitosa campaña Marca Perú, en el sentido de haber incitado comercial y turísticamente, el "orgullo de ser peruano" en el eslogan que le sirve de soporte: "El Perú es una gran marca y todos estamos invitados a ser sus embajadores". No obstante ello, la misma subliminal idea de un país en venta, sobre todo porque la tendencia auspiciada por los teóricos de management posindustrial contemporáneo ha impuesto la idea de que "las empresas deben producir ante todo marcas y no productos" (Klein, 2002: 31), resulta riesgosa. Lo que podría resultar contraproducente, en un contexto determinado por aquella "marketización generalizada", que está desembocando en esa peligrosa asociación modernidad-liberalismo, como analogía de ciudad-mercado; idea que extendida a todo el país, determinaría esa suerte de "triunfo del marketing de la identidad" (Ob. cit. 141), representado por el expandido rótulo Marca Perú, que tiende a abarcar a las tres regiones naturales del Perú: cosa, sierra y selva.

En este sentido, ante aquella asonante $y$ creciente tendencia arquitectónico-urbanística que parecería depararnos una aparentemente nacionalista futura urbe shopping-city-mall, cabe pensar en algunos puntos de escape y salidas viables y posibles a esta tendencia de "marketización generalizada" del espacio urbano. Lo que nos sugeriría una serie de pistas, al momento de intentar solucionar los problemas que han venido agobiando a la ciudad, durante las últimas décadas. De ahí que ensayar un acercamiento analítico y crítico, a las moderna y añejas estructuras de la otrora Ciudad-jardín, nos enfrenta con la capital peruana vista como una ciudad agobiada por la extenuación, el polvo y el cemento. Pues Lima cuadrada, además las continuas y disparatadas construcciones y reconstrucciones dirigidas por las ambiciones políticas y económicas de sus autoridades de turno, al estar infestada de edificaciones tugurizadas, de edificios abandonados, en ruinas o inconclusos, adolece de un deterioro material, simbólico y monumental considerable. Deterioro que podría ser reflejo de un deterioro espiritual y moral que parece comprometer también a todos sus ciudadanos.

Es a esa conjunción de emociones contrariadas, amores e ilusiones que gravitan entre lo tradicional y lo moderno; entre el arquetipo mental que representaría aspiracionalmente a Lima como una urbe histórica o "ciudad museo", para algunos; o como la imagen de un gran centro económico y comercial paraíso del 
consumo, para otros; que podríamos agregarle una consigna que será perentoria para la construcción de una ciudad integral e inclusiva para los próximos años: la de hacer de Lima una ciudad modélica, serena e integral para todos.

Y esto, que se presenta como un reto compartido, aunque pocas veces asumido, hace que quizá, desde su imagen de ciudad colapsada, pese a su cada vez más creciente $y$ ficticia envoltura de modernidad, quede claro que Lima necesita menos supermarkets y más espacios verdes y libres. Por lo que, quizá se deba evaluar las posibilidades fácticas de reformar la ciudad; pero no agudizando las taras que han dejado como herencia los políticos y urbanistas criollos o no criollos de las últimas décadas. Pues, es en este sentido que, sí los males de Lima tienden a diseminarse hasta hacerse patologías nacionales o peruanas; si seguimos la lúcida deducción que a manera de silogismo aristotélico hiciera Abraham Valdelomar: "El Perú es Lima, Lima es el Jirón de la Unión y el Jirón de la Unión es el Palais Concert" ", veremos que el obtuso centralismo peruano y su lógica economicista, en la que el mercado es entendido como sinónimo de desarrollo, está complicando cada vez más el futuro material, simbólico y antropológico de nuestra ciudad-capital.

Sobre todo porque, en aquella analogía o referencia al célebre jirón de Lima cuadrada, podría concretarse también todas las aspiraciones de bienestar, armonía, provecho y futuro de ese gran sector de la población que quiere o preferiría ver a Lima, y al Perú con ella, como una gran ciudad-vitrina comercial, en la que podamos caminar y comprar "todos". Tendencia que nos enfrenta al peligro de caer en esa riesgosa lógica unilateral y economicista que suele asociar la idea de modernizar, solo con la idea de reconstruir y remozar la ciudad a la manera de un inmenso paraíso del consumo. Por lo que, volviendo al silogismo planteado por el célebre autor del "Caballero Carmelo", cabría agregar que el célebre Palais Concert ahora es una gran tienda por departamentos, y que el Perú... No, por ahora tal vez sea mejor olvidar a Abraham Valdelomar.

\section{A guisa de conclusión}

La capital peruana ha experimentado durante los últimos cincuenta años, una serie de cambios que han reconfigurado su multiforme imagen urbana y conurbana, a partir de tránsitos arquitectónicos, urbanísticos, simbólicos, culturales y demográficos, que han terminado por hacer, de la histórica y tradicional Ciudad de los Reyes, un conglomerado híbrido, multicultural y posmoderno; presentándola como una metrópolis que tiende a encerrar, dentro de sus márgenes, los matices culturales, simbólicos, antropológicos y sociales llegados de las tres regiones naturales del Perú. Lo que ha determinado la incidencia de una nueva forma de concebir la peruanidad, aunque desde componentes asimétricos, inestables y menos esencialistas, arribados desde diversos lugares de la cosa, la sierra y la selva peruana, pero asumiendo ribetes identitarios supeditados a un sistema de jerarquías sociohistóricas y antropológicas, que están determinando lo políticamente visible $y$ correcto, frente a su faz fragmentadamente invisible, marginal e incorrecta. $Y$ es desde este punto de análisis, que atiende una noción dual y binaria, que podemos entender aquella tensión permanente y jerárquica entre lo oficial y lo marginal, entre lo ordenado y lo caótico, lo horroroso y lo hermoso, lo diseñado y lo no diseñado, lo formal y lo informal.

Pero no solo eso, sino que en este proceso, en el que parecen integrarse lo local con lo regional-nacional, también tienden a confluir elementos de la cultura global, que van haciendo mucho más complejo este proceso, debido a que lo global tiende a traernos el sueño de la modernidad e hipermodernidad dentro de sí. Se puede decir, como forma de descargo y defensa, que las culturas nacionales renuevan los influjos de las que llegan desde afuera, hasta crear, a manera de pastiche o bricolaje, uno que no obstante aún pueda verse como ajeno se sienta como propio, pero

Citado en Julio Ortega (1986: 13). 
en este acercamiento histórico, urbanístico, sociocultural, que se va transformando en político debido a las incidencias del mercado en el orden urbano, los riesgos y posibilidades que el proyecto de hipermodernización $y$ consumo están determinando en la ciudad, un territorio abigarrado, policéntico e historicista como el limeño, cuyos flujos heterotópicos siguen enfrentándose entre sí, se encuentran con las salidas unilaterales de la tendencia a la "urbanomarketización" contemporánea, auspiciados por el mito antiestético y antihistórico de la operatividad y el progreso. Algo que termina por explicar aquella asonante $\mathrm{y}$ creciente tendencia arquitectónico-urbanística que parece depararnos la urbe shopping-city-mall del futuro, en el que el moderno espacio urbano limeño se presente a la vez como armonioso y excluyente. 


\section{REFERENCIAS}

Anderson, Benedict (1993) Comunidades imaginadas. Buenos Aires: Fondo de Cultura Económica.

Appadurai, Arjun (2001) La modernidad desbocada. Buenos Aires: Trilce-Fondo de Cultura Económica.

Arellano Cueva, Rolando y Burgos Abugattas, David (2003) Ciudad de los Reyes, de los Chávez, los Quispe... Lima: Ediciones EPENSA.

Bustamante Belaúnde, Alberto (1990) De marginales a informales. Lima: DESCO.

Brecht, Bertolt (1980) Historias de almanaque. Madrid: Alianza Editorial.

Deleuze, Gilles (1996) Crítica y clínica. Barcelona: Anagrama.

Deleuze, Gilles (1973) Presentación Sacher- Masoch, Barcelona; Taurus.

De Soto, Hernando (1987) El otro sendero. Bogotá: Instituto Libertad y democracia.

Dupuy, Gabriel (1998) Urbanismo de las redes. Teorías y métodos. Barcelona: Oikos-Tau.

Gálvez, José (1965) Una Lima que se va. Lima: Editorial Universitaria.

Garcilaso de la Vega, Inca (1959) Comentarios Reales de los Incas. Lima-Buenos Aires: Librería Internacional del Perú. Tomo I.

Harth-Terré, Emilio (1976) Formas estéticas. Lima: Editorial Mejía Baca.

Harth-Terré, Emilio (1977) Lima (Ensayos). Lima: Editorial Mejía Baca.

Klein, Naomi (2002) Nologo. El poder de las marcas. Barcelona: Paidos.

Leguía, Jorge Guillermo (1989) Historia y biografía. Lima: Asociación Cultural Integración.

López, Sinesio (1997) Ciudadanos reales e imaginarios. Concepciones, desarrollo y mapas de ciudadanía en el Perú. Lima: Instituto de Diálogo y Propuestas.

Lyotard, Jean François (1990) La condición posmoderna, México: REI.

Mariátegui, José Carlos (1991) 7 ensayos de interpretación de la realidad peruana. Lima: Editorial Horizonte.

Matos Mar, José (2005) Desborde popular y crisis de Estado. Lima: Fondo Editorial del Congreso del Perú.

Matos Mar, José (2012) Perú Estado desbordado y sociedad nacional emergente. Lima: Univerdidad Ricardo Palma, Editorial Universitaria.

Miro Quesada, Aurelio (1994) Lima. Lima: P. L. Villanueva.

Monroy Olivares, César (1998) Teoría del caos. Bogotá: Alfa Omega.

Nugent, José Guillermo (1992) El laberinto de la choledad. Lima: Fundación Friedrich Ebert.

Ojeda, Rafael (2015) "Lima la horrible: desmitificación y modernización de la ciudad contemporánea". En revista Sieteculebras n 36. Cusco, 2015. pp. 28-36. 
Ojeda, Rafael (2011) “Ciudades fracturadas”. En revista Quehacer n 184. Lima, 2011. pp. 60-67.

Ojeda, Rafael (2015) "Miradas sobre el espacio urbano. La ciudad como centro de esencialismos en crisis". En revista Campo letrado, año 4, № 5. Lima, 2015. pp. 52-64.

Ortega, Julio (1986) Cultura y modernización en la Lima del 900. Lima: Centro de Estudios para el Desarrollo y la Participación.

Portocarrero, Gonzalo (2004) Rostros criollos del mal. Lima: Red para el Desarrollo de las Ciencias Sociales del Perú.

Quijano, Anibal (1980) Dominación y cultura. Lo cholo y el conflicto cultural en el Perú. Lima: Mosca Azul Editores.

Salazar Bondy, Sebastián (1974) Lima la horrible. Lima: Peisa.

Sassen, Saskia (1999) La ciudad global. Nueva York, Londres, Tokio. Buenos Aires: Editorial EUDEBA.

Servier, Jean (1969) Historia de la utopía. Caracas: Monte Ávila editores.

Venturi, Robert; Scott Brown, Denise (1971) Aprendiendo de todas las cosas. Barcelona: Editorial Tusquets.

Venturi, Robert, et al. Denise (2000) Aprendiendo de Las Vegas. El simbolismo olvidado de la forma arquitectónica. Barcelona: Gustavo Gili S.A.

Von Eckardt, W. (1982) Live the good life. American Council for the Arts.

Walker, Charles (2012) Colonialismo en ruinas. Lima: IEP -IFEA.

Fecha de recepción: 11-06-16

Fecha de aceptación:22-08-16 
